\title{
Virtual Past Socio-Environmental Systems: An interdisciplinary ECR workshop
}

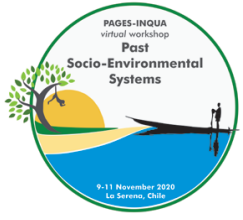

\author{
PASES workshop organizers*
}

\section{Online, 9-11 November 2020}

Effective interdisciplinary collaboration requires trustful interactions and several iteration cycles throughout the scientific process, from the formulation of research questions to the conclusions. Collaborative research is especially challenging among early-career researchers (ECRs), who usually face cultural and geographical barriers among peers, as well as having less experience of networking. In the paleosciences, although the interpretation of historical and paleoenvironmental records requires cross-fertilization of knowledge, this is usually undertaken within the framework of monodisciplinary investigations. As a consequence, conclusions are often drawn as simple, deterministic (either environmental or human) interpretations. This reductive approach minimizes the complexity of the causal relationships involved in human-environmental systems, especially over longer timescales (Fig. 1). Understanding the interplay between past human societies and the natural systems they inhabited may provide us with sustainability strategies for current and future socio-environmental challenges.

The Past Socio-Environmental Systems (PASES; https://www.pases2020.com; pastglobalchanges.org/calendar/2020/127pages/2044) workshop was designed as a joint venture between PAGES ECN (pastglobalchanges.org/ecn) and INQUA ECRs (https://inqua.org/ecr) to foster crossdisciplinary collaborations among the next generation of paleoscientists. This workshop was especially designed for those conducting research at the interface of the climateculture-environment nexus, with experience in proxy-based and modeling records of paleoclimate, archaeology, paleoecology, and human paleodemography.

\section{Without the possibility of meeting in La} Serena, Chile, for an in-person workshop due to the COVID-19 global pandemic, the objectives of the virtual PASES workshop were to bring together ECRs who are open to interdisciplinarity, as well as to promote equal opportunities for participants around the world. The online workshop involved 16 presenters and more than 200 attendees from 26 different countries. The workshop included two three-hour sessions on human paleoecology and synthesis of paleorecords. The last day consisted of an open-table discussion with senior researchers reflecting on community-driven paleoscience questions, and a breakout activity to catalyze scientific collaborations among ECRs.

The virtual workshop began with the Human Paleoecology session, introduced by César Méndez's (Patagonian Ecosystems Investigation Research Center, Chile)

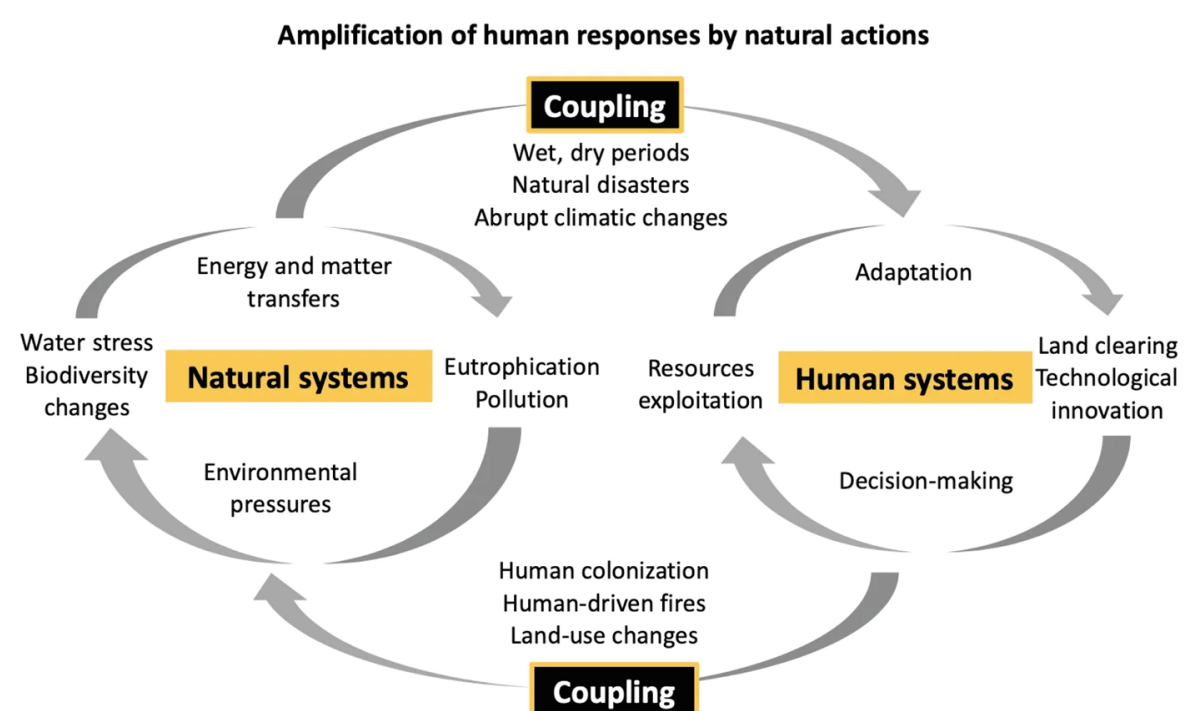

Amplification of natural responses by human actions

Figure 1: Diagram of an idealized past socio-environmental system showing the coupling between natural and human systems.

keynote presentation. Méndez explained the importance of comparative archaeological studies in semiarid regions for understanding human-environmental interactions during the Pleistocene-Holocene transition. Subsequent talks by ECRs gave insights into land-use changes and agricultural practices, the importance of robust chronologies for island colonization processes, and how climate and human pressures can be revealed using sedimentary records in coastal and mountain regions. On day two, keynote speaker Yoshi Maezumi (University of Amsterdam, The Netherlands) spoke about human legacies in the Amazonia through the application of multiproxy evidence from paleoclimatology, archaeobotany, and paleoecology. The following talks by ECRs highlighted the usage of various records (pollen, charcoal, historical archives, bat guano, and ancient eDNA) to tease apart the human and climate drivers explaining past environmental responses. The talks were followed by a lively and interactive Q\&A discussion. For attendees who either couldn't attend or wanted to re-watch the presentations, we shared links privately following the workshop.

The final day was dedicated to interactive and collaborative activities. First, attendees participated in the open discussion "ECRs ask, mentors respond", guided by a panel of four senior scientists. These experienced researchers addressed some of the most pressing questions in the field of past socioenvironmental systems, which were posed by ECRs during the PASES workshop preregistration process. Finally, the breakout activity "Pillars of collaboration" had a strong focus on team science, aiming to initiate conversations for genuine interdisciplinary collaboration revolving around boundary objects - elements that any research collaboration should be built upon (question/ hypothesis, region, field of study, and methodology) to define a joint problem for past socio-environmental systems' research.

Organizing an international virtual workshop was a significant challenge for the Local Organizing Committee - especially in the midst of a pandemic - and particularly in terms of adapting to different time zones and exploring the myriad of different technical options available to maximize attendance. Altogether, the range of expertise from presenters and attendees led to inspiring discussions that provided scientific foci to build new partnerships and plant the seed for the postponed in-person workshop in La Serena, Chile (planned for November 2022; pastglobalchanges.org/calendar/ upcoming/127-pages/1972). For the immediate future, there are virtual PASES networking channels available to encourage active participation and we invite interested ECRs to become involved through the website forum and breakout groups. These virtual workspaces can be a platform for advancement of the PASES outputs, including short articles in the PAGES ECR-led special issue of the Past Global Changes Magazine, and a global database comprising well-known case studies characterized by datasets measuring paleoecological proxies, human population and paleoclimatic changes, as well as integrative methodologies.

\section{AFFILIATIONS}

'See html version: doi.org/10.22498/pages.29.1.58

CONTACT

Xavier Benito: xavier.benito.granell@gmail.com 